\title{
Factors associated with maternal overall quality of life six months postpartum: a cross sectional study from The Norwegian Mother, Father and Child Cohort Study
}

\author{
Lisbeth Valla* (ㅍ, Sølvi Helseth, Milada Cvancarova Småstuen, Nina Misvær and Randi Andenæs
}

\begin{abstract}
Background: Having good Quality of Life (QoL) is essential, particularly for women after childbirth. However, little is known about the factors associated with maternal QoL after giving birth. We aimed to investigate the relationship between characteristics of the mother (socio-demographic variables), selected symptoms (depression and joy/anger), health perception (perception of birth) and possible characteristics of the environment (infant temperament, colic, sleep, parental relationship), with mothers' overall quality of life when the child is 6 months of age.

Methods: This study is based on the Norwegian Mother, Father and Child Cohort Study (MoBa), conducted at the Norwegian Institute of Public Health from June 1999 to December 2008, which included a total of 86,724 children. Maternal QoL was assessed by the Satisfaction With Life Scale. Joy and anger were measured using the Differential Emotional Scale, mothers' mental health was assessed using the Edinburgh Postnatal Depression Scale and satisfaction with relationship was measured using the Relationship Satisfaction Scale. Child temperament was measured using the Infant Characteristics Questionnaire and colic, sleep duration and feelings related to childbirth were assessed by mothers' reports. The associations between life satisfaction and selected variables were analysed using stepwise multiple linear regression models, and the results are presented as effect sizes (ES).
\end{abstract}

Results: Maternal feelings of joy of having a baby $(E S=0.35)$, high relationship satisfaction $(E S=0.32)$, as well as having a baby with normal sleep ( $E S=0.31$ ), are factors associated with higher maternal overall QoL. Postnatal depression was negatively associated with mothers' QoL, and infant colic or child's temperament (fussiness) showed no such association with mothers' QoL.

Conclusions: Health professionals and clinicians should focus on infants sleep but also on supporting joy of motherhood and strengthening relationships of the new parents when they develop health interventions or provide counselling to new mothers and their families.

Keywords: Life quality, Postpartum period, The Norwegian Mother, Father and Child Cohort Study

*Correspondence: lisbeth.valla@oslomet.no

Department of Nursing and Health Promotion, Faculty of Health Sciences, Metropolitan University, Oslo, Norway

\section{Background}

Giving birth and caring for a new infant mark an important transition in life. Although this transition is often exciting and rewarding, it is also a time of vulnerability and many challenges including sleep disruption [1] and heightened psychosocial stress [2], which in turn pose 
a risk to successful emotional and psychological adjustments that ensure quality of life [3]. Theorists have conceptualised quality of life (QoL) in multiple ways, including satisfaction with life [4], subjective well-being [5], and happiness [6]. In medical and health science literature, the term 'health-related quality of life' is most commonly used [7]. Wilson and Cleary propose a theoretical framework for QoL and suggest that symptoms, functional status, health perception, personal factors and environmental characteristics, in addition to biological and physiological factors, are related to an individual's overall quality of life. In the present study, we use the term QoL throughout this article to characterise a broad representation, and define overall quality of life in accordance with Diener (1984) as subjective well-being, relating to an evaluation of how people feel and think about their lives $[8,9]$. QoL constitutes an important goal for individuals and societies with positive consequences for population health $[10,11]$. However, the overall QoL of mothers may be of particular significance, as it may not only affect the mother herself but also the way she interacts with her child and the environment [12].

Several factors impact maternal QoL postpartum. Issues mentioned in the literature such as infant temperament or fussiness, are likely to affect maternal wellbeing [13]. Infant colic and poor sleep behaviour can give rise to negative emotions in the mother that overshadow the joy of being a mother. Colic is infant fussing and crying that occurs in the infant's second or third week of life, lasts more than $3 \mathrm{~h}$ a day and gradually resolves in the third or fourth month $[14,15]$. A study of mothers of new-born's $(N=78)$ reported that those with an infant with colic had more symptoms of depression and lower well-being [16]. During the postpartum period, most women experience significant disturbances in their sleep patterns due to hormonal changes and responsibility for the care of the new-born [17]. Postpartum sleep quality is a critical health index and sleep deprivation is the main source of stress, anxiety, and depression for postpartum women [18, 19]. In addition, women's QoL after childbirth may also be affected by factors related to pregnancy and delivery [20-22] and their marital relationship [3, 23, 24]. Research indicates that women who perceived they were 'very well' cared for during delivery, and women who felt their overall birth experience was 'very positive', were significantly more likely to experience high postnatal functioning [21]. On the other hand, women with a negative childbirth experience are at an increased risk of psychological maladjustment in the first 5 months after giving birth [22].

The majority of previous research focusing on health and quality of life are about the immediate postnatal [21] or postpartum period [25, 26], or risk populations, such as premature birth [27].

There is a paucity of knowledge regarding the role of individual or environmental factors in relation to mothers' QoL after the puerperal period, from large, unselected populations. To provide a rich picture of the factors influencing maternal quality of life, the aim of the present study was to investigate the relationship between characteristics of the mother (i.e. socio-demographic variables), selected symptoms (i.e. depression and joy/ anger), health perception (i.e. perception of birth), and possible characteristics of the environment (i.e. infant temperament, colic, sleep, parental relationship), with mothers' overall quality of life when the child is about 6 months.

\section{Methods}

\section{Participants and sample}

The present study used data from the Norwegian Mother, Father and Child Cohort Study (MoBa), conducted by the Norwegian Institute of Public Health from 1999 through 2008 [28].

All pregnant women in Norway were eligible to participate in $\mathrm{MoBa}$ if they were able to read Norwegian. The MoBa cohort included 114,500 children and 95,200 mothers yielding a response rate of around $41 \%$ [28]. Written informed consent was obtained from all MoBa participants upon recruitment and participants did not receive any financial compensation. The establishment of MoBa and the initial data collection were based on a licence from the Norwegian Data Protection Agency and approval from the Regional Committees for Medical and Health Research Ethics. The MoBa cohort is now based on regulations related to the Norwegian Health Registry Act. The current study is based on version 10 of the MoBa data files and was approved by the Regional Committees for Medical and Health Research Ethics (REKSØ no 9869). Written informed consent was obtained from all MoBa participants. The sample in the present study constitutes 86,724 mothers and children. In the present study twins $(n=1480)$ and triplets $(n=14)$ were excluded.

\section{Measurements \\ Overall quality of life}

Quality of life was measured using the Satisfaction With Life Scale (SWLS) [8] 6 months postpartum. The SWLS includes five items, such as 'The conditions of my life are excellent' and 'I am satisfied with my life', rated on a Likert scale ranging from $1=$ Strongly Disagree, to $7=$ Strongly Agree. Mean scores of the five items were computed. The scale revealed a satisfactory internal consistency, with $\alpha$ 
value 0.89 . Several studies have confirmed the validity of the SWLS $[8,29]$.

\section{Socio-demographic data}

Information on child gender, gestation age and maternal age, maternal educational level, marital status, work status and experience of birth was collected from the MoBa study at 16-20 weeks of pregnancy and 6 months postpartum.

\section{Symptoms}

\section{The Edinburgh postnatal depression scale (EPDS)}

Mothers' mental health was assessed using the Edinburgh Postnatal Depression Scale (EPDS). The EPDS has a sensitivity of $86 \%$ and a specificity of $78 \%$ [30]. Items are scored on a Likert scale ranging from 0 ('no, never') to 3 ('yes, almost all the time'). A 6-item version was used in the MoBa study. The maximum score is 18 , with high scores indicating higher levels of postnatal depression. The internal consistency: Cronbachs $\alpha$ was 0.84 [28].

\section{The differential emotional scale (DES)}

The Differential Emotional Scale [31] consists of a series of subscales that capture various emotions. In the present study, items were selected from the Enjoyment and Anger subscales (DES-IV), and included 3 items of Joy and 3 items of Anger. The respondents rated how often they felt the different emotions on a scale from 1 to 5 where $1=$ seldom $/$ never, and $5=$ very often. Mean scores were computed. The DES has been widely used in research on self-rated affect and has shown good psychometric properties [31, 32].

\section{Feelings related to childbirth}

Feelings related to childbirth were assessed 6 months postpartum based on the single statement 'I felt safe and in good hands', with the following response options; applies well, applies partly, does not apply.

\section{Environment \\ Child's sleep}

Sleep duration at 6 months was assessed using the question, 'How many hours does your child sleep per day'. Response categories were $10 \mathrm{~h}$ or less, 11 to $12 \mathrm{~h}, 13$ to $14 \mathrm{~h}$, and $15 \mathrm{~h}$ or more. We defined that the normal sleep of a child aged around 6 months was $13 \mathrm{~h}$ or more a day.

\section{Infant colic}

Colic was measured at 6 months using one question in the questionnaire, 'Has your child had the following illness/health problem? Infant colic?' The response categories were yes or no. Parents thus answered yes if they thought their child had had colic, and no other diagnostic criteria were needed.

\section{Child temperament}

Child temperament was measured at 6 months using the Infant Characteristics Questionnaire (ICQ) [33]. The original ICQ consists of 24 items describing infant behaviour. Four subscales have been identified; Fussy/ Difficult, Unadaptable, Dull and Unpredictable, with varying internal consistency previously reported $(.79, .75$, $.39, .50)$ (Bates et al. 1979). The scale used in MoBa is the Fussy/Difficult scale (8 items). Mothers rank each item on a 7-point Likert scale [1-7], indicating the level of perceived difficulty of handling the described behaviour. Responses to negatively framed questions on the Fussy/ Difficult scale were reversed, so that lower scores reflect more difficulty. The total score ranged from 7 to 49 and the internal consistency was 0.69 .

\section{Satisfaction with relationship}

Satisfaction with relationship was measured using the Relationship Satisfaction Scale (RS) [34]. RS is a 10-item scale developed for the MoBa study based on previously developed scales. The scale is validated, and showed good psychometric properties [34]. The RS refers to a 'partner' instead of being limited to marital spouses and includes the items 'I am satisfied with the relationship with my partner,' 'My partner and I have problems in our relationship', 'I am very happy in my relationship', 'My partner is generally understanding', and 'We agree on how children should be brought up'. Responses were rated on a 6-point Likert scale ranging from $1=$ Strongly Disagree to $6=$ Strongly Agree. Negative responses were reversed, and items added to form a sum score with a maximum score of 60 .

\section{Statistical analysis}

Data are described with the means and standard deviations (SD) for continuous variables and with frequencies and percentages for categorical data. The associations between life satisfaction and selected variables were analysed using stepwise multiple linear regression models. Variables that were associated with QoL - based on the Wilson \& Cleary model and our clinical knowledge - were included in the multiple regression model. The results are presented as standardized regression coefficients, eg effect sizes as the analysed covariates are measured on very different scales. The Effect size are interpreted as follows: $\mathrm{ES}<01$ is considered small, $E S>0.3$ moderate and ES $>0.5$. The assumptions for linear regression were fulfilled as the residuals were normally distributed. All analyses were considered exploratory, so no correction for multiple testing was performed and 
$p$-values $<0.05$ were considered statistically significant. All statistical analyses were carried out using SPSS, version 25 (IBM Corp, Armonk, NY).

\section{Results}

\section{Sample characteristics}

The participants' characteristics are described in Table 1. The mean age of included mother was 29.8 and over two thirds had medium to high education. A great majority (83.1\%) were employed and almost all were married or co-habiting (97.9\%).

The proportions of infant girls and boys were similar, with $51.0 \%$ of included babies being boys. Almost all of

Table 1 Characteristics of the study population when the child is six months

\begin{tabular}{|c|c|c|c|}
\hline $\begin{array}{l}\text { Child }(N=86,724) \\
\text { mean }(S D)\end{array}$ & n (\%) & mean (SD) & Median (range) \\
\hline Male $\mathbf{n}(\%)$ & $40,205(51.0)$ & & \\
\hline \multicolumn{4}{|l|}{ Missing $(n=7947)$} \\
\hline \multicolumn{4}{|l|}{ Gestation age } \\
\hline$\geq 37$ weeks & 70,815 (95.0) & & \\
\hline $32-36$ weeks & $3231(4.3)$ & & \\
\hline 28-31 weeks & $309(0.4)$ & & \\
\hline$<28$ weeks & $192(0.3)$ & & \\
\hline \multicolumn{4}{|l|}{ Missing $(n=12,177)$} \\
\hline Birth weight in grams & 78,816 & & $3600(500,5960)$ \\
\hline \multicolumn{4}{|l|}{ Missing $(n=7908)$} \\
\hline \multicolumn{4}{|l|}{ Mother $(\mathrm{N}=86,724)$} \\
\hline Maternal age & 82,377 & $29.8(4.5)$ & \\
\hline \multicolumn{4}{|l|}{ Missing $(n=4387)$} \\
\hline \multicolumn{4}{|l|}{ Maternal education ${ }^{a}$} \\
\hline low & $26,607(34.0)$ & & \\
\hline medium & $32,941(42.0)$ & & \\
\hline high & $18,836(24.0)$ & & \\
\hline \multicolumn{4}{|l|}{ Missing $(n=8340)$} \\
\hline \multicolumn{4}{|l|}{ Work status ${ }^{b}$} \\
\hline Education & $4930(6.0)$ & & \\
\hline Employed & $68,153(83.1)$ & & \\
\hline Other & 8938 (10.9) & & \\
\hline \multicolumn{4}{|l|}{ Missing $(n=4703)$} \\
\hline \multicolumn{4}{|l|}{ Marital status ${ }^{c}$} \\
\hline Married/co-habiting & 80,333 (97.9) & & \\
\hline Missing $(n=4640)$ & & & \\
\hline
\end{tabular}

${ }^{a}$ Education at 16-20 weeks of pregnancy: low education = completed primary school and or lower and upper secondary school. Medium education $=$ completed college $/$ university $1-3$ years. High education $=$ completed college $/$ university 4 years

${ }^{\mathrm{b}}$ Work Status at $16-20$ weeks of pregnancy: education $=$ student, at home, trainee, military service. Employed =employed in the public or private sector. Other $=$ unemployed

${ }^{\mathrm{C}}$ Marital status at $16-20$ weeks of pregnancy the included babies were born after 37GA (95\%), thus the mean birth weight was $3600 \mathrm{~g}$ (Table 2).

Results from the stepwise linear regression analyses estimating associations between selected factors and mothers' overall life satisfaction are presented in Table 3. As described in the method section, each block of covariates was added step by step. In block 1 , lower age of the mother, higher level of education and living alone were all associated with higher life satisfaction scores. Age and educational level remained significant throughout the regression analyses. The second step of the linear regression analysis, adjusted for confounding variables such as age, educational level and marital status, showed that low depression scores, higher feelings of joy, lower feelings of anger and higher feelings of having been taken care of during birth, were all significantly related to higher life satisfaction.

The third step of the analysis, during which the environmental factors were entered, and the model was adjusted for variables from step 2, showed that neither infant colic nor the child's.

temperament were no longer significantly associated with mothers' life satisfaction, while children sleeping $13 \mathrm{~h}$ or more a day remained statistically significant. With $E S=0.31$ the effect of sufficient infant's sleep on mother's QoL was moderate. Living alone lost its significant association, while higher level with partnership satisfaction scores was significantly associated with higher QoL. Women who were happy in their relationship exhibited a moderate effect size of this variable with QoL $(E S=0.32)$. Moreover, joy of motherhood was also significantly associated with QoL, reaching a moderate effect size $(E S=0.35)$. Finally, the effect of depression was negative and regarded as small with $(\mathrm{ES}=0.12)$. The final model explained $49 \%$ of the variance in mothers' quality of life.

\section{Discussion}

Our results, from a large Norwegian representative sample 6 months after birth, suggest that feelings of joy of having a baby, high relationship satisfaction, as well as having a baby with normal sleep, are factors associated with higher maternal overall QoL. Postnatal depression was negatively associated with mothers' QoL, and infant colic or child temperament (fussiness) showed no such association with mothers' QoL.

In accordance with previous studies, our results indicated that positive emotions such as feelings of joy of motherhood are an important variable in maternal overall QoL [3, 35-37]. One explanation for these findings may be that joy and positive emotions in motherhood serve as a buffer against stress $[38,39]$, and are important components of connectedness in the parent-child attachment that enhances psychological health and 
Table 2 Description of study variables

\begin{tabular}{|c|c|c|c|c|}
\hline Variable (scoring) & Scale & Range & Mean & SD \\
\hline Overall quality of life (high scores = higher QoL) & SWLS & $5-35$ & 28.8 & 4.9 \\
\hline \multicolumn{5}{|l|}{ Missing $n=1684$} \\
\hline Depression (high scores = more depression) & EPDS & $0-18$ & 3.1 & 3.2 \\
\hline \multicolumn{5}{|l|}{ Missing $n=1710$} \\
\hline Joy (high scores = more joy) & DES-J & $2-15$ & 11.9 & 2.1 \\
\hline \multicolumn{5}{|l|}{ Missing $n=9109$} \\
\hline Anger (high scores = more anger) & DES-A & $2-15$ & 6.2 & 2.2 \\
\hline \multicolumn{5}{|l|}{ Missing $n=9131$} \\
\hline Fussiness (higher scores $=$ more fussy) & $\mathrm{ICQ}$ & $7-49$ & 16.4 & 5.6 \\
\hline \multicolumn{5}{|l|}{ Missing $=4321$} \\
\hline Relationship satisfaction (higher scores $=$ higher satisfaction) & RS & $10-60$ & 52.6 & 7.2 \\
\hline \multicolumn{5}{|l|}{ Missing $=6308$} \\
\hline & & & $\%$ & \\
\hline \multicolumn{5}{|l|}{ Feeling safe during birth } \\
\hline applies well & & & 84.5 & \\
\hline applies partly & & & 13.3 & \\
\hline does not apply & & & 2.2 & \\
\hline \multicolumn{5}{|l|}{ Missing $n=2333$} \\
\hline Normal sleep of child ( $13 \mathrm{~h}$ or more a day) & & & 92.6 & \\
\hline Missing $=3695$ & & & & \\
\hline
\end{tabular}

well-being [40]. Wilson and Cleary (1995) theorised that psychological symptoms and emotions influence physical or social functioning, role functioning, mental health and general health perceptions [7]. Thus, the feelings of joy mothers experience as a result of having children are likely to contribute to their global happiness $[7,9]$. Consequently, children may benefit as well. Indeed, joy and positive emotions in the parent-child interaction have been associated with positive outcomes for the child [12]. However, our results showed that postnatal depression was negatively associated with mothers' overall QoL. A majority of studies emphasise the postpartum period as a particularly vulnerable time during which women are at increased risk of mental disorders [41-43], and that postpartum depression has negative consequences on maternal QoL [44].

Maternal QoL was also positively affected by environmental characteristics such as high relationship satisfaction and infant sleep quality $(13 \mathrm{~h}$ or more a day at 6 months). Previous research has demonstrated that relationship dissatisfaction [3, 22-24, 45], and poor infant sleep quality are associated with higher maternal depression scores [46-48] and lower QoL [3]. Nelson et al. (2014) proposed in a previous review that parents of young children are unhappy to the extent that they encounter sleep disturbance and troubled marriages. Among married/cohabiting couples, the partner is usually the major provider of various types of social support and living in an emotionally supportive relationship may protect their physical and psychological health in demanding situations. A person's perception of relationship quality may therefore directly affect their wellbeing by eliciting positive emotions or by serving as a buffer against the potentially harmful effects of other external stressors [22].

Notably, neither infant colic nor child temperament (fussiness) showed any association with mothers' QoL. Although factors such as infant colic and fussiness are highly stressful and strongly associated with maternal depression $[49,50]$ when they are ongoing, our results show that when the child is 6 months, a history of colic and fussiness has no effect on mothers' QoL. This may indicate that these problems are transient and that the mother's QoL at 6 months is not affected by such previous challenges. However, higher levels of maternal social support during pregnancy and postpartum have previously been associated with lower rates of maternal reported infant colic [51].

Our findings have important implications for practice and clinical counselling. First, mothers' overall QoL is a significant indicator of positive mental health that may affect the parent-child dyad, which in turn may influence the child's development $[10,12]$. Our results indicate that healthcare providers should raise awareness about mothers' joy of motherhood, children's sleep habits and encourage parents to look after 
Table 3 Stepwise multivariate linear regression analysis (standardised beta coefficients) with mothers' quality of life as the dependent variable

\begin{tabular}{|c|c|c|}
\hline Independent Variables & Effect size & $P$-value \\
\hline \multicolumn{3}{|l|}{ Block 1} \\
\hline Age, years & -0.06 & $<0.001$ \\
\hline Level of education ( 1 - 3) & 0.13 & $<0.001$ \\
\hline Marital status (not married/cohabitating as ref.) & -0.02 & $<0.001$ \\
\hline \multicolumn{3}{|l|}{ Block 2} \\
\hline Age, years & -0.02 & $<0.001$ \\
\hline Level of education ( 1 - 3) & 0.09 & $<0.001$ \\
\hline Marital status (not married/cohabitating as ref.) & -0.02 & $<0.001$ \\
\hline Depression (EPDS 6-item) (high scores $=$ more depression) & -0.15 & $<0.001$ \\
\hline Joy (DES-J) (high scores = more joy) & 0.48 & $<0.001$ \\
\hline Anger (DES-A) (high scores= more anger) & -0.13 & $<0.001$ \\
\hline Feeling safe during birth (lower scores = more confidence) & -0.03 & $<0.001$ \\
\hline \multicolumn{3}{|l|}{ Block 3} \\
\hline Age, years & -0.01 & 0.12 \\
\hline Level of education ( 1 - 3) & 0.08 & $<0.001$ \\
\hline Marital status (not married/cohabitating as ref.) & -0.001 & 0.76 \\
\hline Depression (EPDS 6-item) (high scores = more depr.) & -0.12 & $<0.001$ \\
\hline Joy (DES-J) (high scores = more joy) & 0.35 & $<0.001$ \\
\hline Anger (DES-A) (high scores= more anger) & -0.06 & $<0.001$ \\
\hline Feeling safe during birth (lower scores = less confidence) & -0.02 & $<0.001$ \\
\hline Colic (no colic as ref.) & -0.004 & 0.18 \\
\hline Child's temperament (ICQ) (lower scores = less fussy) & -0.006 & 0.06 \\
\hline Child sleeping more than $13 \mathrm{~h}$ a day ( $\leq 13 \mathrm{~h}$ as ref.) & 0.31 & $<0.001$ \\
\hline Relationship satisfaction (RS) (higher scores = more satisfaction) & 0.32 & $<0.001$ \\
\hline
\end{tabular}

$R^{2}=0.49$

their relationship. Health professionals should inform both parents of the importance of enhancing partnership relations and partner support. Secondly, our findings highlight the transient nature of the phenomenon of colic, and the short period in which it places a burden on parents. Our findings may be considered in the design of effective health promotion strategies that enable new mothers to maintain optimal health and QoL for themselves and their infants. Identifying health promotion factors that may be particularly positive for life satisfaction in this phase may enable policymakers to prioritise and develop interventions or programmes or provide social support that will benefit individuals and/ or families.

Although the present study has many strengths, including a large national sample, the results must be interpreted in light of several methodological limitations. First, the assessment of feelings related to childbirth, sleep or colic did not include validated or objective measures. The results may also be impacted by a selection bias because of attrition in the MoBa study, such as higher maternal age, and fewer health-related risks among those who did not participate in the study [28]. Hence, the results must be interpreted with some caution.

\section{Conclusions}

In conclusion, the present study's results show that joy of motherhood, relationship satisfaction and infant sleep are the most important factors for mothers' overall QoL 6 months after birth, while a history of infant colic showed no association. Health professionals and clinicians should focus on these issues when they develop health interventions or provide counselling to new mothers and their families.

\section{Abbreviations}

MoBa: The Norwegian Mother, Father and Child Cohort Study; QoL: Quality of Life.

\section{Acknowledgements}

We are grateful to all the families in Norway who are taking part in this ongoing cohort study.

\section{Authors' contributions}

LV: Responsibility for the study design, participated in the analytic framework of the study, interpretation and in the writing of the manuscript. SH: Primary 
responsibility for the study design, Participated in the analytic framework of the study, with the data interpretation, and in the writing of the manuscript. MCS: Was involved in and supervised the statistical analysis. NM: Has been involved in the study design. Participated in the analytic framework of the study and has critically revising the manuscript for important intellectual content. RA: Has been involved in the study design, participated in the analytic framework of the study, statistical analysis, and in writing of the manuscript. All the authors have given their final approval of the final version of the manuscript.

\section{Funding}

The Norwegian Mother, Father and Child Cohort Study is supported by the Norwegian Ministry of Health and Care Services and the Ministry of Education and Research, NIH/NIEHS (contract no N01-ES-75558), NIH/NINDS (grant no.1 UO1 NS 047537-01 and grant no.2 U01 NS 047537-06A1).

\section{Availability of data and materials}

The data that support the findings of this study are available from Norwegian Institute of Public Health, but restrictions apply to the availability of these data, which were used under license for the current study, and so are not publicly available. Data are however available from the author upon reasonable request and with permission of the Norwegian Institute of Public Health.

\section{Declarations}

\section{Ethics approval and consent to participate}

Not applicable.

The current study is based on version 10 of the MoBa data files and was approved by the Regional Committees for Medical and Health Research Ethics (REK-SØ no 9869). Written informed consent was obtained from all MoBa participants.

The Norwegian Mother and Children Cohort study, The Norwegian Institute of Public Health, have granted permission to access and use the dataset.

\section{Consent for publication}

Not applicable.

\section{Competing interests}

The authors declare that they have no competing interests.

Received: 18 February 2021 Accepted: 30 November 2021

Published online: 03 January 2022

\section{References}

1. Hagen EW, Mirer AG, Palta M, Peppard PE. The sleep-time cost of parenting: sleep duration and sleepiness among employed parents in the Wisconsin sleep cohort study. Am J Epidemiol. 2013;177(5):394-401.

2. Reid KM, Taylor MG. Social support, stress, and maternal postpartum depression: a comparison of supportive relationships. Soc Sci Res. 2015;54:246-62.

3. Nelson SK, Kushlev K, Lyubomirsky S. The pains and pleasures of parenting: when, why, and how is parenthood associated with more or less well-being? Psychol Bull. 2014;140(3):846-95.

4. Diener E. Subjective well-being. Psychol Bull. 1984;95(3):542-75.

5. Diener E, Lucas RE. Subjective well-being: three decades of progress. Psychol Bull. 1999;125(2):276.

6. Brülde B. Happiness and the good life. Introduction and conceptual framework. An Interdisciplinary Forum on Subjective Well-Being. 2007:8(1):1-14.

7. Wilson IB, Cleary PD. Linking clinical variables with health-related quality of life. A conceptual model of patient outcomes. Jama. 1995;273(1):59-65.

8. Diener E, Emmons RA, Larsen RJ, Griffin S. The satisfaction with life scale. J Pers Assess. 1985;49(1):71-5.

9. Diener E, Pressman SD, Hunter J, Delgadillo-Chase D. If, why, and when subjective well-being influences health, and future needed research. Appl Psychol Health Well Being. 2017;9(2):133-67.
10. Howell RT, Kern ML, Lyubomirksy S. Health benefits: Meta- analytically determining the impact of well-being on objective health outcomes. Health Psychol Rev. 2007;1:83-136.

11. Steptoe A, Deaton A, Stone AA. Subjective wellbeing, health, and ageing. Lancet. 2015;385(9968):640-8.

12. Sameroff A. The transactional model of development: how children and contexts shape each other. Washington, DC: American Psychological Association; 2009

13. Brenning K, Soenens B, Mabbe E, Vansteenkiste M. Ups and downs in the joy of motherhood: maternal well-being as a function of psychological needs, personality, and infant temperament. J Happiness Stud. 2019;20(1):229-50

14. Wolke D, Bilgin A, Samara M. Systematic Review and Meta-Analysis: Fussing and Crying Durations and Prevalence of Colic in Infants. J Pediatr. 2017;185:55-61 e4.

15. Wessel MA, Cobb JC, Jackson EB, Harris GS Jr, Detwiler AC. Paroxysmal fussing in infancy, sometimes called colic. Pediatrics. 1954;14(5):421-35.

16. Abacı FB, Gökçe S, Tuygun N, Karacan CD, Öner Ö. Psychosocial status and quality of life in mothers of infants with colic. Turk J Pediatr. 2013;55(4):391-5.

17. Hunter LP, Rychnovsky JD, Yount SM. A selective review of maternal sleep characteristics in the postpartum period. J Obstet Gynecol Neonatal Nurs. 2009;38(1):60-8.

18. Henderson J, Alderdice F, Redshaw M. Factors associated with maternal postpartum fatigue: an observationalstudy. BMJ Open. 2019;9(7):e025927.

19. Giallo R, Gartland D, Woolhouse H, Brown S. "I didn't know it was possible to feel that tired": exploring the complex bidirectional associations between maternal depressive symptoms and fatigue in a prospective pregnancy cohort study. Arch Womens Ment Health. 2016;19(1):25-34.

20. Rezaei N, Tavalaee Z, Sayehmiri K, Sharifi N, Daliri S. The relationship between quality of life and methods of delivery: a systematic review and meta-analysis. Electron Physician. 2018;10(4):6596-607.

21. Michels A, Kruske S, Thompson R. Women's postnatal psychological functioning: the role of satisfaction with intrapartum care and the birth experience. J Reprod Infant Psychology. 2013;31(2):172-82.

22. Lemola S, Stadlmayr W, Grob A. Maternal adjustment five months after birth: the impact of the subjective experience of childbirth and emotional support from the partner. J Reprod Infant Psychology. 2007;25(3):190-202.

23. Delicate A, Ayers S, McMullen S. A systematic review and meta-synthesis of the impact of becoming parents on the couple relationship. Midwifery. 2018;61:88-96.

24. Luhmann M, Hofmann W, Eid M, Lucas RE, King L. Subjective wellbeing and adaptation to life events: a Meta-analysis. J Pers Soc Psychol. 2012;102(3):592-615.

25. Van der Woude DAA, Pijnenborg JMA, de Vries J. Health status and quality of life in postpartum women: a systematic review of associated factors. Eur J Obstet Gynecol Reprod Biol. 2015;185:45-52.

26. Zubaran C, Foresti K. Investigating quality of life and depressive symptoms in the postpartum period. Women and Birth. 2011;24(1):10-6.

27. Hill PD, Aldag JC. Maternal perceived quality of life following childbirth. J Obstetric, Gynecologic, Neonatal Nursing. 2007;36(4):328-34.

28. Magnus $P$, Birke C, Vejrup K, Haugan A, Alsaker E, Daltveit AK, et al. Cohort profile update: the Norwegian mother and child cohort study (MoBa). Int J Epidemiol. 2016;45(2):382-8.

29. Pavot W, Diener E, Colvin CR, Sandvik E. Further validation of the satisfaction with life scale: evidence for the cross-method convergence of wellbeing measures. J Pers Assess. 1991;57(1):149-61.

30. Cox JL, Holden JM, Sagovsky R. Detection of postnatal depression. Development of the 10-item Edinburgh postnatal depression scale. Br J Psychiatry J Ment Sci. 1987;150:782-6.

31. Izard CE, Libero DZ, Putnam P, Haynes OM, Geen R. Stability of emotion experiences and their relations to traits of personality. J Pers Soc Psychol. 1993;64(5):847-60.

32. Blumberg SH, Izard CE. Affective and cognitive characteristics of depression in 10- and 11-year-old children. J Pers Soc Psychol. 1985;49(1):194-202

33. Bates JE, Freeland CA, Lounsbury ML. Measurement of infant difficultness. Child Dev. 1979;50(3):794-803.

34. Røysamb E, Vittersø J, Tambs K. The relationship satisfaction scale - psychometric properties. Norsk epidemiologi. 2014;24(1-2):187-94. 
35. Nelson SK, Kushlev K, English T, Dunn EW, Lyubomirsky S. In defense of parenthood: children are associated with more joy than misery. Psychol Sci. 2013;24(1):3-10.

36. Berntsen D, Rubin DC, Siegler IC. Two versions of life: emotionally negative and positive life events have different roles in the organization of life story and identity. Emotion. 2011;11(5):1190-201.

37. Deaton A, Stone AA. Evaluative and hedonic wellbeing among those with and without children at home. Proc Natl Acad Sci U S A. 2014:111(4):1328-33.

38. Tugade MM, Fredrickson BL. Resilient individuals use positive emotions to bounce back from negative emotional experiences. J Pers Soc Psychol. 2004;86(2):320-33.

39. Cohn MA, Fredrickson BL, Brown SL, Mikels JA, Conway AM. Happiness unpacked: positive emotions increase life satisfaction by building resilience. Emotion. 2009;9(3):361-8.

40. Deci EL, Ryan RM. Self-determination theory: a macrotheory of human motivation, development, and health. Can Psychology/Psychologie Canadienne. 2008:49:182-5.

41. O'Hara MW, McCabe JE. Postpartum depression: current status and future directions. Annu Rev Clin Psychol. 2013;9:379-407.

42. Vesga-López O, Blanco C, Keyes K, Olfson M, Grant BF, Hasin DS. Psychiatric disorders in pregnant and postpartum women in the United States. Arch Gen Psychiatry. 2008;65(7):805-15.

43. Munk-Olsen T, Laursen TM, Pedersen CB, Mors O, Mortensen PB. New parents and mental disorders: a population-based register study. Jama. 2006;296(21):2582-9.

44. Slomian J, Honvo G, Emonts $P$, Reginster JY, Bruyère O. Consequences of maternal postpartum depression: A systematic review of maternal and infant outcomes. Womens Health (Lond). 2019;15:1745506519844044.

45. Doss BD, Rhoades GK, Stanley SM, Markman HJ. The effect of the transition to parenthood on relationship quality: an 8-year prospective study. J Pers Soc Psychol. 2009;96(3):601-19.

46. Dørheim SK, Bondevik GT, Eberhard-Gran M, Bjorvatn B. Sleep and depression in postpartum women: a population-based study. Sleep. 2009:32(7):847-55.

47. Hall WA, Moynihan M, Bhagat R, Wooldridge J. Relationships between parental sleep quality, fatigue, cognitions about infant sleep, and parental depression pre and post-intervention for infant behavioral sleep problems. BMC Pregnancy Childbirth. 2017;17(1):104.

48. Saxbe DE, Schetter CD, Guardino CM, Ramey SL, Shalowitz MU, Thorp J, et al. Sleep quality predicts persistence of parental postpartum depressive symptoms and transmission of depressive symptoms from mothers to fathers. Ann Behav Med. 2016;50(6):862-75.

49. Vik T, Grote V, Escribano J, Socha J, Verduci E, Fritsch M, et al. Infantile colic, prolonged crying and maternal postnatal depression. Acta Paediatr. 2009;98(8):1344-8.

50. Radesky JS, Zuckerman B, Silverstein M, Rivara FP, Barr M, Taylor JA, et al. Inconsolable infant crying and maternal postpartum depressive symptoms. Pediatrics. 2013;131(6):e1857-64

51. Alexander CP, Zhu J, Paul IM, Kjerulff KH. Fathers make a difference: positive relationships with mother and baby in relation to infant colic. Child Care Health Dev. 2017;43(5):687-96.

\section{Publisher's Note}

Springer Nature remains neutral with regard to jurisdictional claims in published maps and institutional affiliations.

Ready to submit your research? Choose BMC and benefit from:

- fast, convenient online submission

- thorough peer review by experienced researchers in your field

- rapid publication on acceptance

- support for research data, including large and complex data types

- gold Open Access which fosters wider collaboration and increased citations

- maximum visibility for your research: over $100 \mathrm{M}$ website views per year

At BMC, research is always in progress.

Learn more biomedcentral.com/submissions 